\title{
Current practices and perceived barriers to tobacco treatment delivery among healthcare professionals from 15 European countries. The EPACTT Plus project
}

\author{
Charis Girvalaki 1,2, Enkeleint A. Mechili2,3, Sophia Papadakis 1,2,4,5, Katerina Nikitara' ${ }^{1}$, Andrey Demin ${ }^{6}$, Antigona Trofor ${ }^{7,8}$, \\ Arben Lila ${ }^{9}$, Arusyak Harutyunyan ${ }^{10}$, Aurela Saliaj ${ }^{3}$, Deska Dimitrievska ${ }^{11}$, Francisco Rodriguez Lozano ${ }^{1,12}$, George Bakh- \\ turidze $^{13}$, Javier Ayesta ${ }^{14},{ }^{2}$ rzysztof Przewozniak ${ }^{15,16}$, Maria Sofia Cattaruzza ${ }^{17,18}$, Marija Zdraveska ${ }^{11}$, Mihaela Lovš $\mathrm{e}^{19}$, \\ Biljana Kilibarda ${ }^{20}$, Otto Stoyka ${ }^{21}$, Panagiotis Behrakis ${ }^{22,23}$, Pierre Bizel24, Polina Starchenko', Shkumbin Spahija ${ }^{9}$, Cornel \\ Radu-Loghin', Constantine I. Vardavas ${ }^{1,25}$
}

\section{ABSTRACT}

INTRODUCTION The latest evidence-based Guidelines for Treating Tobacco Dependence highlight the significant role of healthcare professionals in supporting smokers interested to quit. This study aimed to identify the current practices of healthcare professionals in Europe and perceived barriers in delivering tobacco treatment to their patients who smoke.

METHODS In the context of EPACTT-Plus, collaborating institutions from 15 countries (Albania, Armenia, Belgium, Italy, France, Georgia, Greece, Kosovo, Romania, North Macedonia, Russia, Serbia, Slovenia, Spain, Ukraine) worked for the development of an accredited eLearning course on Tobacco Treatment Delivery available at http:// elearning-ensp.eu/. In total, 444 healthcare professionals from the wider European region successfully completed the course from December 2018 to July 2019. Cross-sectional data were collected online on healthcare professionals' current practices and perceived barriers in introducing tobacco-dependence treatment into their daily clinical life.

RESULTS At registration, $41.2 \%$ of the participants reported having asked their patients if they smoked. Advise to quit smoking was offered by $47.1 \%$ of the participants, while $29.5 \%$ reported offering assistance to their patients who smoked in order to quit. From the total number of participants, $39.9 \%$ regarded the lack of patient compliance as a significant barrier. Other key barriers were lack of: interest from the patients $(37.4 \%)$, healthcare professionals training $(33.1 \%)$, community resources to refer patients $(31.5 \%)$, and adequate time during their everyday clinical life $(29.7 \%)$.

CONCLUSIONS The identification of current practices and significant barriers is important to build evidence-based guidelines and training programs (online and/or live) that will improve the performance of healthcare professionals in offering tobacco-dependence treatment for their patients who smoke.

\section{AFFILIATION}

1 European Network for Smoking and Tobacco Prevention, Brussels, Belgium

2 Clinic of Social and Family Medicine, Medical School, University of Crete, Heraklion, Greece 3 Department of Healthcare, Faculty of Health, University of Vlora, Vlore, Albania

4 Division of Prevention and Rehabilitation,

University of Ottawa Heart Institute, Ottawa, Canada 5 Faculty of Medicine, University of Ottawa, Ottawa,

Canada

6 Institute of Leadership and Healthcare

Management, I.M. Sechenov First Moscow State

Medical University, Moscow, Russia

7 University of Medicine and Pharmacy 'Grigore

T.Popa', lasi, Romania

8 AER PUR Romania, Bucharest, Romania

9 Kosovo Advocacy and Development Center,

Prishtina, Kosovo

10 Turpanjian School of Public Health, American University of Armenia, Yerevan, Armenia

11 Respiratory Society of North Macedonia, Skopje, North Macedonia

12 Comité Nacional de Prevención del Tabaquismo, Madrid, Spain

13 Tobacco Control Alliance of Georgia, Tbilisi, Georgia

14 University of Cantabria, Cantabria, Spain

15 Foundation 'Smart Health - Health in 3D', Warsaw, Poland

16 Maria Sklodowska-Curie National Research Institute of Oncology, Warsaw, Poland

17 Department of Public Health \& Infectious Diseases, Sapienza University, Rome, Italy 18 SITAB, Società Italiana di Tabaccologia, Rome, Italy

19 Slovenian Coalition for Tobacco Control, Ljubljana, Slovenia

20 Institute of Public Health of Serbia, Belgrade, Serbia

21 Kyiv Health Center, Kyiv, Ukraine

22 George D. Behrakis Research Laboratory, Athens,

Greece

23 Hellenic Cancer Society, Athens, Greece

24 Wallionie Tabac Prevention, Brussels, Belgium

25 Medical School, University of Crete, Heraklion, Greece 
CORRESPONDENCE TO

Charis Girvalaki. European Network for Smoking and Tobacco Prevention, Brussels, Belgium. E-mail: charis@tobcontrol.eu ORCID ID http://orcid. org/0000-0001-6849-0972

\section{KEYWORDS}

barriers, Europe, healthcare professionals, tobaccodependence treatment, eLearning, current practices

Received: 21 October 2019

Revised: 2 December 2019

Accepted: 3 December 2019

\section{INTRODUCTION}

Smoking cessation is one of the main strategies suggested by the World Health Organization's (WHO) MPOWER package against the tobacco epidemic through Guidelines that call parties to facilitate accessibility and affordability for treatment of tobacco dependence ${ }^{1}$.

Through the latest evidence-based Guidelines for Treating Tobacco Dependence, the European Network for Smoking and Tobacco Prevention (ENSP) highlighted the importance of healthcare professionals' role in supporting smokers interested in receiving tobacco treatment by organizing a treatment plan, combining behavioral counseling and pharmacotherapy, while non-pharmacological therapy should remain an option when it is best prefered by the patients ${ }^{2,3}$. The $5 \mathrm{As}$ model is considered an evidence-based intervention for integrating tobacco-dependence treatment into clinical settings and has been shown to increase quit attempts and cessation rates. It consists of the following fundamental strategies: Ask all patients if they smoke, Advise patients who smoke to quit, Assess readiness to quit, Assist patients to make a quit attempt, and Arrange follow-up meetings ${ }^{2,4}$.

Live training interventions have been found to increase the rate of $5 \mathrm{As}$ delivery ${ }^{5-7}$. However, recent reviews show that there is a gap in the use of advanced computer-based medical education approaches on tobacco-treatment training for healthcare professionals ${ }^{8}$.

Various factors influence healthcare professionals' performance in offering smoking cessation support, such as time restrictions, lack of training, reimbursement, knowledge and skills ${ }^{9}$, experience, and task perception ${ }^{10,11}$. Among others, the existing scientific work has identified additional barriers, such as the competing demands, the lack of familiarity with effective treatments, and perceptions of low receptivity to tobacco interventions ${ }^{12,13}$.

Based on the above, this study aimed to identify the current practices of healthcare professionals in Europe and perceived barriers in delivering tobacco treatment to their patients who smoke, important factors that will help us build evidencebased guidelines and training programs (online and/ or live) to improve the performance of healthcare professionals in offering tobacco-dependence treatment for their patients who smoke.

\section{METHODS}

In the context of EPACTT-Plus (European Network for Smoking Prevention's Accredited Curriculum on Tobacco Treatment-Plus), collaborating institutions from 15 (Albania, Armenia, Belgium, Italy, France, Georgia, Greece, Kosovo, Romania, North Macedonia, Russia, Serbia, Slovenia, Spain, Ukraine) countries worked for the development of an accredited by the European Accreditation Council for Continuing Medical Education (2 CME) eLearning course on Tobacco Treatment Delivery available at http:// elearning-ensp.eu/. In total, 444 healthcare professionals from the wider European region successfully completed the course from December 2018 to July 2019.

Cross-sectional data on healthcare professionals' current practices and perceived barriers in introducing tobacco-dependence treatment into 
their daily clinical life were collected online, after consent, at the beginning of the course.

Current practices of healthcare professionals in delivering each of the 4As (ask, advise, assist, arrange) were assessed by the participant responses: 'Never', 'Few times', 'Half times', 'Many times', and 'Always'; specifically, when asked how frequently during the past month they ask their patients about their smoking status (Ask) and documented tobacco use in the patient's medical record; advised them to quit smoking (Advise); provided assistance with quitting (Assist); or arranged follow-up support (Arrange). For Assist, we examined whether the healthcare professional provided brief smoking cessation counselling (3-5 minutes), worked with the patient to set a date to quit smoking, gave written materials about quitting smoking, and discussed or prescribed available quit-smoking medications.

Barriers that might limit the capacity of the healthcare professionals to offer smoking cessation treatments were assessed by the participant responses: 'Not at all important', 'Less important', 'Neutral', and 'Important', by rating a list of 10 statements. The statements were: "patients not interested', 'patients do not comply', 'lack of impact on patients', 'lack of time', 'lack of/insufficient reimbursement', 'lack of patient education material', 'lack of training', 'lack of community resources to refer patients', 'complexity of smoking cessation guidelines', and 'other health problems take priority'.

\section{Statistical analysis}

Frequencies and percentages are used to describe healthcare professionals' current practices and perceived barriers in delivering tobacco treatment to their patients who smoke. Data were analysed with the IBM SPSS statistical software 23.0.

\section{RESULTS}

Among the participants, $73.4 \%$ were female with almost half $(43.6 \%)$ aged $<30$ years. The majority worked in public sector units $(73.9 \%)$ in urban areas (81.9\%), and on a full-time basis $(82.0 \%)$. Also, $68.9 \%$ had not previously participated in smoking-cessation training and were non-smokers $(67.8 \%)$. With regard to the existence of smoking cessation aids in their clinics, $56.5 \%$ reported having available a process to screen and document the smoking status of patients while $28.0 \%$ had self-help materials for smokers and $15.4 \%$ consult forms to guide them through tobaccotreatment interventions.

Table 1 presents the current practices of healthcare professionals in terms of the 4As delivery. Before the course, $41.2 \%$ of the participants reported investigating their patients smoking status while $31.8 \%$ documented the smoking status of their patients. In addition to the above, advise to quit smoking was offered by $47.1 \%$ of the participants.

Table 1. Assessment and frequency of current practices in delivering tobacco treatment to their patients who smoke, among participants of the EPACTT eLearning programme, as collected at registration, 2018-2019 $(\mathrm{N}=414)$

\begin{tabular}{|c|c|c|c|c|c|}
\hline \multirow[t]{2}{*}{ Current practices } & \multicolumn{5}{|c|}{ Delivery of 1 As } \\
\hline & $\begin{array}{l}\text { Vever } \\
\text { II }(\%)\end{array}$ & $\begin{array}{c}\text { Few limes } \\
\text { n }\left(\%_{0}\right)\end{array}$ & $\begin{array}{c}\text { Hall times } \\
\text { In (\%) }\end{array}$ & $\begin{array}{c}\text { Vany limes } \\
\text { In }\left({ }^{\circ}\right)\end{array}$ & $\begin{array}{c}\text { Always } \\
\text { In (\%) }\end{array}$ \\
\hline Ask & $71(16.0)$ & $40(9.0)$ & $81(18.2)$ & 69 (15.5) & $183(41.2)$ \\
\hline Document smoking status of the patient & $142(32.0)$ & $43(9.7)$ & $66(14.9)$ & $52(11.7)$ & $141(31.8)$ \\
\hline Advise - Quit smoking & $58(13.1)$ & $36(8.1)$ & $63(14.2)$ & $78(17.6)$ & $209(47.1)$ \\
\hline Assist - Brief counseling (3-5 minutes) & $80(18.0)$ & 75 (16.9) & $78(17.6)$ & $80(18.0)$ & $131(29.5)$ \\
\hline Assist - Set quit date & $144(32.4)$ & $68(15.3)$ & $92(20.7)$ & $66(14.9)$ & $74(16.7)$ \\
\hline Assist - Provide self-help materials & $161(36.3)$ & $55(12.4)$ & $99(22.3)$ & $48(10.8)$ & $81(18.2)$ \\
\hline Assist - Discuss medications ${ }^{a}$ & $127(30.8)$ & $68(16.5)$ & $91(22.1)$ & $54(13.1)$ & $72(17.5)$ \\
\hline Assist - Prescribe medications & $235(52.9)$ & $60(13.5)$ & $70(15.8)$ & $34(7.7)$ & $45(10.1)$ \\
\hline Arrange & $174(39.2)$ & 77 (17.3) & $78(17.6)$ & $49(11.0)$ & $66(14.9)$ \\
\hline
\end{tabular}

a Missing values $=32$. 
Table 2. Assessment and frequency of perceived barriers in delivering tobacco treatment to their patients who smoke, among participants of the EPACTT eLearning programme, as collected at registration, 2018-2019 $(\mathrm{N}=$ 444)

\begin{tabular}{|c|c|c|c|c|}
\hline Perceived barriers & $\begin{array}{l}\text { Not at all } \\
\text { important } \\
\text { n }(\%)\end{array}$ & $\begin{array}{l}\text { Less important } \\
\qquad n(\%)\end{array}$ & $\begin{array}{l}\text { Veutral } \\
\text { n }(\%)\end{array}$ & $\begin{array}{l}\text { Important } \\
\text { n(\%) }\end{array}$ \\
\hline Patients not interested & $23(5.2)$ & $61(13.7)$ & $194(37.4)$ & $166(37.4)$ \\
\hline Patients do not comply & $25(5.6)$ & $68(15.3)$ & $174(39.2)$ & $177(39.9)$ \\
\hline Lack of impact on patients & $30(6.8)$ & $81(18.2)$ & $224(50.5)$ & $109(24.5)$ \\
\hline Lack of time & $47(10.6)$ & $108(24.3)$ & $157(35.4)$ & $132(29.7)$ \\
\hline Lack of/insufficient reimbursement & $79(17.8)$ & $119(26.8)$ & $133(30.0)$ & $113(25.5)$ \\
\hline Lack of patient education material & $27(6.1)$ & $108(24.3)$ & $186(41.9)$ & $123(27.7)$ \\
\hline Lack of training & $34(7.7)$ & 79 (17.8) & $184(41.4)$ & $147(33.1)$ \\
\hline Lack of community resources to refer patients & $33(7.4)$ & $84(18.9)$ & $187(42.1)$ & $140(31.5)$ \\
\hline Complexity of smoking cessation guidelines & $62(14.0)$ & $139(31.3)$ & $157(35.4)$ & $86(19.4)$ \\
\hline Other health problems take priority & $59(13.3)$ & $105(23.6)$ & $165(37.2)$ & $115(25.9)$ \\
\hline
\end{tabular}

Almost one in three $(29.5 \%)$ offered assistance to their patients to quit smoking by providing brief counselling (3-5 minutes), 16.7\% helped them to set a quit date, $18.2 \%$ provided self-help materials, $17.5 \%$ discussed medication, $10.1 \%$ prescribed medication to patients who were willing to quit while $14.9 \%$ of the healthcare professionals arranged follow-up meetings.

In Table 2 the perceived barriers to implementing tobacco-treatment interventions, are presented. Of the participants, $39.9 \%$ regarded the lack of compliance by the patients as a significant barrier. Other important barriers were the lack of interest from the patients $(37.4 \%)$, healthcare professionals training $(33.1 \%)$, community resources to refer patients $(31.5 \%)$, and adequate time during their everyday clinical life (29.7\%) .

\section{DISCUSSION}

The results of our study reveal that at registration, participants of the EPACTT eLearning reported insufficient rates of 4As delivery, especially in providing assistance and arranging follow-up meetings with their patients. In addition, patient-related factors such as lack of interest as well as lack of healthcare professionals training and lack of adequate time in everyday clinical life were reported as the most important factors preventing the implementation of tobacco-treatment interventions with patients who smoked. Several previous studies also show that rates of tobaccotreatment delivery remain sub-optimal in Europe ${ }^{14,15}$. This evidence along with the fact that the tobacco-use prevalence in Europe has remained stable for the past years ${ }^{16}$ reinforce the importance of joint actions for the implementation of WHO FCTC Article 14.

Previous training interventions have been found to increase the rate of $5 \mathrm{As}$ delivery ${ }^{5-7}$. A cluster randomised controlled trial also found that a 1-hour practice-tailored training significantly increased the frequency at which 'ask' and 'advise' were delivered $^{17}$. Additionally, online education using new technologies has been found to potentially increase educational opportunities, supplement teaching and decrease distance barriers in health professional education ${ }^{18}$. However, more studies evaluating the efficacy of online training programs are necessary.

The importance of identifying and addressing the perceived barriers in order to increase the delivery of tobacco-treatment interventions from healthcare professionals has been highlighted in previous studies ${ }^{9,19,20}$ while a recent study found that healthcare professionals that had positive experiences from delivering tobacco-treatment interventions, and who felt competent, were positively associated with performing the $5 \mathrm{As}$ and having organizational support with Assist and Arrange. However, personal tobacco use was also negatively associated with Advice and Arrange ${ }^{21}$. 
Our results show that time constraints and insufficient training on how to treat tobacco dependence were among the most important barriers. Other studies confirm these results ${ }^{9-11}$. In addition, low receptivity of tobacco interventions from the patients is highlighted as a barrier from other studies ${ }^{12,13}$.

The importance of continuing medical education training programmes has also been acknowledged and affects professional competence, future clinical practice, and patient outcomes ${ }^{22,23}$. We propose that translating evidence-based behaviouralchange interventions into practice must be aided by evidence-based guidelines ${ }^{2}$, educational curricula, training courses, policy recommendations, and implementation strategies for Europe ${ }^{24}$.

\section{Strengths and limitations}

There are a limited number of studies reporting data from an eLearning platform. Our study presented results on current practices and barriers of tobaccotreatment delivery from healthcare professionals of the wider European region, as reported through the ENSP eLearning platform. This study collected data from healthcare professionals during their first registration in the online programme, and hence the results may not be generalizable to the population of healthcare professionals in Europe. Healthcare professionals who participated in the eLearning program might have been more motivated or interested in tobacco, and hence more likely to ask and support their patients. On the other hand, participants might have been lacking in skills, which may be the reason why they registered in the course. Moreover, by design, our study was not able to evaluate the effectiveness of the course in changing their current practices with regard to implementing the 4As, for which a followup would provide valuable insight. We note that we did not enquire about 'Assess' in the present study to shorten the total length of the survey, as it was considered less important than the other 4As in terms of the desired outcomes of the intervention. Finally, giving four options for rating the barriers' significance may have confused the participants' responses.

\section{CONCLUSIONS}

The identification of current practices and significant barriers is important to improve the existing evidence-based guidelines and training programs (online and/or live) that affect the performance of healthcare professionals in offering tobaccodependence treatment to their patients who smoke. The present study has highlighted the actions, at the European level, that are necessary to reinforce the implementation of WHO FCTC Article 14 synergically with the other of the Articles.

\section{REFERENCES}

1. World Health Organization. WHO Report on the Global Tobacco Epidemic: The MPOWER Package. Geneva, Switzerland: World Health Organization; 2008. https:// www.who.int/tobacco/mpower/2008/en/. Accessed September 22, 2019.

2. European Network for Smoking and Tobacco Prevention. 2018 Guidelines for Treating Tobacco Dependence. 4th ed. Brussels, Belgium: European Publishing; 2018. http:// elearning-ensp.eu/pluginfile.php/1052/mod_resource/ content/2/guidelines_2018_english.pdf. Accessed September 22, 2019.

3. Mechili EA, Girvalaki C, Saliaj A, et al. WHO FCTC Article 14 enforcement in Albania: An urgent issue to tackle. Tob Prev Cessation. 2019;5(February):1-4. https://doi. org/10.18332/tpc/103126

4. Fiore MC, Jaén CR, Baker TB, et al. Treating tobacco use and dependence: 2008 update. Rockville, MD: US Department of Health and Human Services; 2008.

5. Girvalaki C, Papadakis S, Vardavas C, et al. Training General Practitioners in Evidence-Based Tobacco Treatment: An Evaluation of the Tobacco Treatment Training Network in Crete (TiTAN-Crete) Intervention. Health Educ Behav. 2018;45(6):888-897. doi:10.1177/1090198118775481

6. Papadakis S, McDonald PW, Pipe AL, et al. Effectiveness of telephone-based follow-up support delivered in combination with a multi-component smoking cessation intervention in family practice: a clusterrandomised trial. Prev Med. 2013;56(6):390-397. doi:10.1016/j.ypmed.2013.02.018

7. Papadakis S, Cole AG, Reid RD, et al. Increasing rates of tobacco treatment delivery in primary care practice: evaluation of the Ottawa Model for Smoking Cessation. Ann Fam Med. 2016;14(3):235-243. doi:10.1370/afm.1909

8. Semwal M, Whiting P, Bajpai R, et al. Digital education for health professions on smoking cessation management: Systematic review by the Digital Health Education Collaboration. J Med Internet Res. 2019;21(3):e13000. doi:10.2196/13000

9. Stead M, Angus K, Holme I, et al. Factors influencing European GPs' engagement in smoking cessation: a multi-country literature review. Br J Gen Pract. 2009;59(566):682-690. doi:10.3399/bjgp09X454007

10. Flemming K, Graham H, McCaughan D, et al. Health 
professionals' perceptions of the barriers and facilitators to providing smoking cessation advice to women in pregnancy and during the post-partum period: a systematic review of qualitative research. BMC Public Health. 2016;16(1):290. doi:10.1186/s12889-016-2961-9

11. Svavarsdóttir MH, Hallgrímsdóttir G. Participation of Icelandic nurses in smoking cessation counselling. J Clin Nurs. 2008;17(10):1335-1341. doi:10.1111/j.1365-2702.2006.01874.x

12. Braun BL, Fowles JB, Solberg LI, et al. Smoking-related attitudes and clinical practices of medical personnel in Minnesota. Am J Prev Med. 2004;27(4):316-322. doi:10.1016/j.amepre.2004.07.010

13. Zillich AJ, Aquilino ML, Farris KB. Knowledge and attitudes about smoking cessation among pharmacy technicians. J Am Pharm Assoc. 2004;44(5):578-582. doi:10.1331/1544-3191.44.5.578.zillich

14. Everatt R, Zolubiene E, Grassi MC. Smoking cessation practice among family doctors in Lithuania: a Survey. Clin Ter. 2016;167(5):161-167. PMID:27845484.

15. Jiménez-Ruiz CA, Miranda JA, Pinedo AR, et al. Prevalence of and attitudes towards smoking among Spanish health professionals. Respiration. 2015;90(6):474-480. doi:10.1159/000441306

16. European Union. Special Eurobarometer 458: Attitudes of Europeans towards tobacco and electronic cigarettes. 2017. doi:10.2875/804491

17. Verbiest ME, Crone MR, Scharloo M, et al. Onehour training for general practitioners in reducing the implementation gap of smoking cessation care: a cluster-randomized controlled trial. Nicotine Tob Res. 2013;16(1):1-10. doi:10.1093/ntr/ntt100

18. Frehywot S, Vovides $\mathrm{Y}$, Talib Z, et al. E-learning in medical education in resource constrained low-and middleincome countries. Hum Resour Health. 2013;11(1):4. doi:10.1186/1478-4491-11-4

19. Patelarou E, Vardavas CI, Ntzilepi P, et al. Nursing education and beliefs towards tobacco cessation and control: a cross-sectional national survey (GHPSS) among nursing students in Greece. Tob Induc Dis. 2011;9(1):4. doi:10.1186/1617-9625-9-4

20. Pipe A, Sorensen M, Reid R. Physician smoking status, attitudes toward smoking, and cessation advice to patients: an international survey. Patient Educ Couns. 2009;74(1):118-123. doi:10.1016/j.pec.2008.07.042

21. Martínez Martínez C, Castellano Y, Andrés A, et al. Factors associated with implementation of the 5A's smoking cessation model. Tob Induc Dis. 2017;15(November). doi:10.1186/s12971-017-0146-7

22. Price D. Continuing medical education, quality improvement, and organizational change: implications of recent theories for twenty-firstcentury CME. MED TEACH. 2005;27(3):259-268. doi:10.1080/01421590500046270

23. Shumway JM, Harden RM. AMEE Guide No. 25: The assessment of learning outcomes for the competent and reflective physician. MED TEACH. 2003;25(6):569-584. doi:10.1080/0142159032000151907

24. PESCE project. General Practitioners and the economics of smoking cessation in Europe. Policy recommendations and implementation strategies. 2008. Available at: https:// www.freivontabak.ch/images/pdf/downloads/PESCE. pdf. Accessed September 22, 2019.

\section{ACKNOWLEDGEMENTS}

The authors wish to express their thanks to the Global Bridges tobaccodependence treatment network, and in particular Katie Kemper and Taylor Hays for their support.

CONFLICTS OF INTEREST

The authors have completed and submitted the ICMJE Form for Disclosure of Potential Conflicts of Interest and none was reported.

\section{FUNDING}

This work was supported by Global Bridges: Healthcare Alliance for Tobacco Dependence Treatment, and Pfizer Independent Grants for Learning and Change (GB- 25944945).

\section{PROVENANCE AND PEER REVIEW}

Commissioned; externally peer-reviewed. 